\title{
Dyspareunia Treated By Bilateral Pudendal Nerve Block
}

\author{
Gregory Amend, Yimei Miao, Felix Cheung, John Fitzgerald, Brian Durkin, S. Ali \\ Khan and Srinivas Pentyala* \\ Departments of Urology and Anesthesiology, Stony Brook Medical Center, USA
}

Received: November 19, 2013; Accepted: March 13, 2014, Published: March 14, 2014

*Corresponding author: Srinivas Pentyala, Department of Anesthesiology, Stony Brook Medical Center, Stony Brook, NY 11794-8480, New York, USA; Tel: 631-444-2974; Fax: 631-444-2907; E-mail: srinivas.pentyala@stonybrook.edu

\begin{abstract}
In this report, we present a patient with refractory superficial dyspareunia of unclear etiology, who was successfully managed with a bilateral pudendal nerve block. Initial workup failed to identify an obvious source for the pain and first-line therapy for postmenopausal superficial dyspareunia was not effective. A bilateral pudendal nerve block alleviated the problem to three years followup. In this report, we review the current dyspareunia literature and propose a diagnostic algorithm.
\end{abstract}

Keywords: Dyspareunia; Organ prolapse; Vaginitis; Pudendal nerve block; Vulvar vestibulitis

\section{Introduction}

Dyspareunia, genital pain with intercourse, is a highly prevalent problem amongst female patients and a common cause of sexual dysfunction [1]. Dyspareunia is commonly classified as superficial or deep depending on the location of the pain. Superficial dyspareunia results from pain at the vaginal introitus upon penile penetration, whereas deep dyspareunia occurs with deep thrusting of the penis. Multiple studies have determined that the majority of women with dyspareunia report superficial pain associated with penile entry [2-4]. The etiology of dyspareunia is often multi-factorial, and therefore consistent characteristics of patients with dyspareunia are lacking [4]. The presentation may vary from localized pain to generalized disinterest in sexual experiences, making dyspareunia one of the more difficult clinical obstacles to treat with good patient outcome $[4,5]$. In this report, we present a case of superficial dyspareunia managed with bilateral pudendal nerve block.

\section{Case Report}

A 48year old postmenopausal female on hormone replacement therapy was seen for vaginal pain associated with sexual intercourse for 6 months duration. Intercourse and sexual habits had been normal and unrestricted prior to onset of pain. Pain was present at the distal $1 / 3^{\text {rd }}$ of the vagina and was described as stabbing in nature. Pain scale was $8 / 10$ and was present only with superficial penetration during intercourse. There was no pain upon voiding or at rest. Symptoms recurred with every sexual attempt and resulted in inability to complete the sexual act. The patient's last sexual attempt was 2 weeks prior to presentation. The patient was in a stable long term marriage with no history of physical, sexual, or emotional abuse. Patient denied use of alcohol, tobacco, and illicit drugs. There was no history of psychiatric conditions, endocrine abnormalities, neurologic illnesses, pelvic trauma, sexually transmitted infections, incontinence, pelvic floor disorders, urological problems, endometriosis, or vaginal stenosis. The patient previously had multiple abdominal incisions, including two elective $\mathrm{C}$-sections and a total abdominal hysterectomy for dysfunctional uterine bleeding 4 years prior to presentation. 2 years after the hysterectomy, the patient complained of abdominal pain and underwent laparoscopic lysis of adhesions with a successful outcome. The patient also reported one uncomplicated urinary tract infection, which resolved with antibiotics several years prior to presentation. Menarche was at 12 years of age and periods were irregular until the hysterectomy. The patient was previously seen by her gynecologist, who had recommended vaginal lubrication and psychotherapy. Patient refused psychotherapy and was using vaginal lubricants with minimal effect.

Physical examination revealed normal external genitalia and a non-tender clitoris with a normal clitoral hood. Speculum examination was unremarkable. The urethra was non-tender and bimanual examination revealed pain present at the distal $1 / 3^{\text {rd }}$ of the vagina upon digital penetration of the vaginal orifice. No vaginal or adnexal masses were palpable. Rectal examination revealed no masses and good anal sphincter tone. A hormone panel which included estradiol, testosterone, and prolactin, was normal. Pelvic organs were assessed by trans-abdominal ultrasound, which demonstrated normal adnexa without cystic or solid masses, and no sonographic signs of inflammation or free fluid in the pelvic cul-de-sac. A cystoscopy was performed and was unremarkable.

The patient underwent a one-time bilateral transgluteal fluoroscopy-guided pudendal nerve block achieved with injection of 3 cc $0.25 \%$ bupivacaine under sedation. Following the procedure, intercourse was painless and orgasm was achieved. The patient returned to her normal pattern of sexual habits with no pain after three years of follow-up care. 


\section{Discussion}

Dyspareunia has been estimated to have a lifetime incidence of over $60 \%$ in women [1]. Dyspareunia is much more common in women than men and has been associated with pain initiating from vulvar surfaces to deep perineal structures [4]. Although the distinction between superficial and deep dyspareunia may help to better characterize and diagnose the cause of the pain, dyspareunia is a multifaceted disease.

The vagina is a dilatable musculo-membranous conduit which originates at the vaginal orifice and extends to the middle cervix. The vagina has several important functions to support normal sexual functioning and serves as an outflow tract for menstrual fluid and comprises the inferior aspect of the birth canal, where it communicates superiorly with the cervix and inferiorly with the vaginal vestibule [6]. The vestibule of the vagina is defined as the area bound by the labia minora and contains the vaginal orifice as well as several para-vaginal structures such as the external urethral orifice and ducts of the greater and lesser vestibular glands [6].

The pudendal nerve originates from the ventral rami of S2S4 and supplies the striated muscles of the perineum and most of the perineal skin, distributing branches to the distal vaginal wall, clitoris, and labia [7-9]. The pudendal nerve exits the pelvic cavity via the greater sciatic foramen, inferior to the piriformis muscle. The nerve then immediately courses onto the dorsal surface of the sacrospinous ligament to pass through the lesser sciatic foramen, where it enters the perineum on the inner surface of the obturator internus muscle. In the perineum, the pudendal nerve divides into its three terminal branches-the dorsal nerve of the clitoris/penis, the perineal nerve, and the inferior rectal nerve. In females, the perineal nerve innervates the muscles of the perineum as well as the skin of the labia major, labia minora, and vaginal vestibule $[7,9]$.

The innervation of the vagina is both somatic and autonomic in nature. As previously stated, the inferior $1 / 5^{\text {th }}$ to $1 / 4^{\text {th }}$ of the vagina is somatically innervated via the perineal nerve $[6,9]$. The remaining areas of the vagina receive visceral innervation from the uterovaginal nerve plexus, which extends to pelvic viscera from the inferior hypogastric plexus. These fibers carry efferent sympathetic and parasympathetic input, as well as visceral afferent innervation to the upper vaginal wall $[6,8]$. Due to this anatomical organization between somatic and visceral innervation, the majority of the vagina does not contain somatic sensory corpuscles. Therefore, the ability to detect touch and pain is principally located in the most inferior aspect of the organ [6].

Somatic nociception is carried principally by A delta fibers, prevalent in the vulva and returned to the central nervous system via the pudendal nerve. Although C fibers innervate the viscera within the vagina and cervix, afferent pain information from these fibers is not typically conducted except in circumstances of repeated mechanical or chemical stimulation [5].

Table 1 demonstrates an extensive list of etiologies of superficial and deep dyspareunia. Because dyspareunia is often multi-factorial, it is very difficult to diagnose and treat effectively.
Table 1: Differential diagnosis of dyspareunia according to location of the pain.

\begin{tabular}{|c|c|c|}
\hline Superficial & Deep & Both \\
\hline Atopic dermatitis & Adenomyosis & Anxiety \\
\hline $\begin{array}{l}\text { Bartholin's gland } \\
\text { cyst or abscess }\end{array}$ & $\begin{array}{l}\text { Adnexal tumors and } \\
\text { infections }\end{array}$ & Depression \\
\hline $\begin{array}{l}\text { Candidal } \\
\text { vulvovaginitis }\end{array}$ & Bladder stones & $\begin{array}{l}\text { Iatrogenic pain post } \\
\text { gastrointestinal } \\
\text { or genitourinary } \\
\text { instrumentation }\end{array}$ \\
\hline Contact dermatitis & Cervical polyps & Insufficient lubrication \\
\hline $\begin{array}{l}\text { Female genital } \\
\text { mutilation } \\
\text { syndrome }\end{array}$ & Cervicitis & Perineal ulcers or scars \\
\hline Herpetic neuralgia & Chemotherapy & Sjopgren's syndrome \\
\hline Interlabial masses & Crohn's disease & Sexual abuse \\
\hline Imperforate hymen & Diseases of the clitoris & Urogenital atrophy \\
\hline $\begin{array}{l}\text { Lichen Sclerosis } \\
\text { Piriformis } \\
\text { syndrome }\end{array}$ & Diverticulitis & $\begin{array}{l}\text { Vaginal and pelvic trauma } \\
\text { or surgery }\end{array}$ \\
\hline $\begin{array}{l}\text { Pudendal } \\
\text { neuropathy }\end{array}$ & Dysmenorrhea & \\
\hline Skene's duct cyst & Endometriosis & \\
\hline Urethritis & Endometritis & \\
\hline $\begin{array}{l}\text { Urinary tract } \\
\text { infection }\end{array}$ & Episiotomy scars & \\
\hline Vaginal cyst & Fibroid uterus & \\
\hline $\begin{array}{l}\text { Congenital } \\
\text { vaginal septum } \\
\text { malformations }\end{array}$ & Interstitial cystitis & \\
\hline Vaginal stenosis & $\begin{array}{l}\text { Intravaginal foreign } \\
\text { bodies }\end{array}$ & \\
\hline Vaginitis & $\begin{array}{l}\text { Irritable bowel } \\
\text { syndrome }\end{array}$ & \\
\hline Vaginismus & Levator ani spasm & \\
\hline \multirow[t]{18}{*}{ Vulvar Vestibulitis } & Lower ureteral stones & \\
\hline & Malfunction of IUD & \\
\hline & Osteitis pubis & \\
\hline & Pelvic adhesions & \\
\hline & $\begin{array}{l}\text { Pelvic congestion } \\
\text { syndrome }\end{array}$ & \\
\hline & Pelvic fracture & \\
\hline & $\begin{array}{l}\text { Pelvic inflammatory } \\
\text { disease }\end{array}$ & \\
\hline & Pelvic malignancies & \\
\hline & Pelvic organ prolapse & \\
\hline & Pelvic radiation & \\
\hline & Pelvic tuberculosis & \\
\hline & $\begin{array}{l}\text { Radiation seed } \\
\text { implantation }\end{array}$ & \\
\hline & Rectal prolapse & \\
\hline & Retroverted uterus & \\
\hline & Ulcerative colitis & \\
\hline & $\begin{array}{l}\text { Ureteralor urethral } \\
\text { steinstrasse }\end{array}$ & \\
\hline & Urethral diverticulum & \\
\hline & $\begin{array}{l}\text { Thrombosed } \\
\text { hemorrhoids } \\
\text { Vaginal stenosis }\end{array}$ & \\
\hline
\end{tabular}




\section{History and Physical Examination}

(Include detailed pelvic and rectal examination and evaluation of pudendal nerve function by perineal sensation and anal sphincter tone)

\section{$\downarrow$}

\section{Laboratory Testing}

(CBC, Chem. 8 and serum estradiol, am testosterone, prolactin and sex hormone binding globulin, thyroid panel and pap smear if uterus is present)

$\downarrow$

Initial Imaging Studies

(Pelvic and transvaginal ultrasound/duplex Doppler, as well as proctoscopy and/or colonoscopy for any suspected lower GI tract issues)

$\downarrow$

\section{If ultrasound or physical findings are abnormal}

(CT scan with and without contrast and or upright MRI, MRV of the pelvis)

Figure 1: Diagnostic workup of dyspareunia.

In Figure 1, we propose a diagnostic scheme to work up a patient with dyspareunia.

We recommend that after a detailed history and pelvic exam, if a clear etiology for the pelvic pain cannot be identified, the patient should be instructed to keep a pain diary that outlines the nature of the pain, exacerbating or alleviating factors, whether it is superficial or deep, or positional dependent. The patient should be instructed to apply water-soluble sexual or surgical lubricant during intercourse. If condoms are being used, the patient should be checked for the presence of latex allergy. A moisturizing skin lotion may be recommended as an alternative lubricant unless the patient is using a condom or other latex product. Further recommendations that may be appropriate are a change in coital position, local estrogen treatment in post-menopausal women, and consultation with a sex therapist and/or psychiatrist. Should the above measures fail, a bilateral transgluteal or transvaginal pudendal nerve block may be therapeutic in the case of superficial dyspareunia.

As a result of the anatomy and function of the pudendal nerve, a bilateral pudendal nerve block may be an effective therapy for superficial dyspareunia. Current literature indicates that a pudendal nerve block is a therapeutic option for pudendal neuralgia and vulvodynia $[10,11]$ and may be accomplished by a transgluteal, or transvaginal approach $[10,12,13]$. Although this patient did not suffer from any adverse effects, a pudendal nerve block is not without complications. One study reported the procedure to cause headache, muscle ache, fecal incontinence, urinary incontinence and leg numbness [14]. This case demonstrates that more prospective studies are essential to further determine the role of bilateral pudendal nerve block in the diagnosis and treatment of female patients with dyspareunia.

\section{References}

1. Glatt AE, Zinner SH, McCormack WM (1990) The prevalence of dyspareunia. Obstet Gynecol 75(3): 433-436.

2. Meana M, Binik YM, Khalife S, Cohen D (1997) Dyspareunia: sexual dysfunction or pain syndrome? J Nerv Ment Dis 185(9): 561-569.

3. Meana M1, Binik YM, Khalife S, Cohen DR (1997) Biopsychosocial profile of women with dyspareunia. Obstet Gynecol 90(4): 583-589.

4. Heim LJ (2001) Evaluation and differential diagnosis of dyspareunia. Am Fam Physician 63(8): 1535-1544.

5. Steege JF, Zolnoun DA (2009) Evaluation and treatment of dyspareunia. Obstet Gynecol 113(5): 1124-1136.

6. Moore KL, Dalley AF, Agur AMR (2014) Clinically oriented anatomy. ( $7^{\text {th }}$ edn.), Wolters Kluwer/Lippincott Williams \& Wilkins Health, Philadelphia, USA, pp. 1134.

7. Tagliafico A, Perez MM, Martinoli C (2013) High-Resolution ultrasound of the pudendal nerve: normal anatomy. Muscle Nerve 47(3): 403-408.

8. Song YB, Hwang K, Kim DJ, Han SH (2009) Innervation of vagina: microdissection and immunohistochemical study. J Sex Marital Ther 35(2): 144-153.

9. Abdi S, Shenouda P, Patel N, Saini B, Bharat Y, et al. (2004) A novel technique for pudendal nerve block. Pain Physician 7(3): 319-322.

10. Cok OY, Eker HE, Cok T, Akin S, Aribogan A, et al. (2011) Transsacral S2-S4 nerve block for vaginal pain due to pudendal neuralgia. J Minim Invasive Gynecol 18(3): 401-404.

11. McDonald JS, Rapkin AJ (2012) Multilevel local anesthetic nerve blockade for the treatment of generalized vulvodynia: a pilot study. J Sex Med 9(11): 2919-2926.

12. Kobak AJ, Evans EF, Johnson GR (1956) Transvaginal pudendal nerve block; a simple procedure for effective anesthesia in operative vaginal delivery. Am J Obstet Gynecol 71(5): 981-989. 
13. Iremashvili VV, Chepurov AK, Kobaladze KM, Gamidov SI (2010) Periprostatic local anesthesia with pudendal block for transperineal ultrasound-guided prostate biopsy: a randomized trial. Urology 75(5): 1023-1027.
14. Vancaillie T, Eggermont J, Armstrong G, Jarvis S, Liu J, et al. (2012) Response to pudendal nerve block in women with pudendal neuralgia. Pain Med 13(4): 596-603. 